\title{
COVID-19 infection is a major cause of acute telogen effluvium
}

\author{
Khalifa E. Sharquie ${ }^{1} \mathbb{D} \cdot$ Raed I. Jabbar $^{2}$ (D) \\ Received: 9 July 2021 / Accepted: 25 August 2021 / Published online: 31 August 2021 \\ (c) Royal Academy of Medicine in Ireland 2021
}

\begin{abstract}
Background Acute telogen effluvium is a non-scaring hair loss, usually occurs 3 months after the stressful event that causes hair shedding, and lasts up to 6 months. It can be associated with post COVID-19 infection.

Objective To study the possible effects of COVID-19 on the hair growth cycle and the relationship between COVID-19 and acute telogen effluvium.

Patients and methods This is an observational cross-sectional study that had been conducted during the period from September 2020 to March 2021 years. Thirty-nine patients with post COVID-19 hair loss are confirmed by polymerase chain reaction (PCR) or antibody testing. Hair pull test was carried out to confirm the diagnosis and severity of telogen effluvium. Results Thirty-nine patients were evaluated; their ages ranged from 22 to 67 years with a mean and SD of $41.3 \pm 11.6$ years with 36 (92.3\%) females and $3(7.69 \%)$ males.

All patients with a diagnosis of ATE were enrolled in this study and had a laboratory-confirmed diagnosis of prior SARSCoV-2 infection; 15 (38.46\%) patients reported mild symptoms, 24 (61.53\%) patients presented with moderate disease, and no patient required hospitalization. They all experienced excessive hair loss within 2-3 months after infection. Pull tests were strongly positive ( $>10-50 \%$ with a mean of $35 \%$ of pulled hair away from scalp).

Conclusion COVID-19 infection is now a frequent and a common cause of acute telogen effluvium. Hence, clinicians should be aware about the relation between this infection and this pattern of hair loss. Drugs that have been used for the treatment of COVID-19 were excluded as a cause of acute telogen effluvium.
\end{abstract}

Keywords Acute $\cdot$ COVID-19 $\cdot$ Drugs $\cdot$ Hair loss $\cdot$ Telogen effluvium

\section{Introduction}

Coronavirus disease 2019 (COVID-19), a pandemic infection caused by severe acute respiratory syndrome coronavirus type 2 (SARS-CoV-2), was first recorded from Wuhan in central China in December 2019 [1, 2].

COVID-19 has lately been connected to skin manifestations like vesicular, maculopapular, urticarial acroischemic lesions, and others [3]. Telogen effluvium (TE) is one of the

Raed I. Jabbar

ismailraid40@gmail.com

Khalifa E. Sharquie

ksharquie@ymail.com

1 Department of Dermatology, College of Medicine, University of Baghdad, Medical City Teaching Hospital, Baghdad, Iraq

2 Department of Dermatology, Fallujah Teaching Hospital, Al-Anbar Health Directorate, Anbar, Iraq most common forms of hair loss that is characterized by a diffuse hair loss and has many known triggers like stressful events, drugs, endocrine disease, major surgery, febrile illnesses, and nutritional deficiencies [4]. Acute TE (ATE) is a non-scaring hair loss, usually occurs 3 months after the event that causes hair loss, and lasts up to 6 months, while chronic TE exceeds 6 months. ATE is self-limited disease characterized by unusual hair shedding (more than 100 shed hair per day) as a consequence of an abrupt shift of the hair follicles from anagen to telogen phase [5].

The hair cycle composed of three phases: anagen, catagen, and telogen. The anagen phase is the growth phase of the hair cycle. Approximately $85 \%$ of hair is within the anagen phase at a time, and this phase lasts between 2 and 6 years. The catagen phase is the transition phase which occurs when anagenic follicle receives a signal and it ends the growth phase. The catagen phase lasts for 1 to 2 weeks. The telogen phase, which is additionally referred to as the resting phase, is the last stage of the hair cycle. This phase lasts 3 to 5 weeks until the anagen phase is resumed $[6,7]$. 
So, the aim of the current work is to study the possible effects of COVID-19 on the hair and the relationship between COVID-19 and ATE.

\section{Patients and methods}

This is an observational cross-sectional study that had been conducted during the period from September 2020 to March 2021 years. Thirty-nine patients with hair loss that started after COVID-19 infection confirmed by polymerase chain reaction (PCR) or antibody testing with no history of TE or previous hair fall were included in the present study.

The study followed the Declaration of Helsinki principles, and informed consent was obtained from each patient after an explanation about the nature of the study. The gleaned data included age, gender, and clinical presentations. In addition, a thorough history was taken from every patient regarding onset of COVID-19 infection, onset of hair shedding, associated systemic or dermatological signs and symptoms, disease severity, and what treatment they received.

Hair pull test by grasping 50 to 60 hair between thumb, index, and middle fingers in frontal, occipital, and both temporal regions of the scalp was performed, and the test was considered positive if more than $10 \%$ of pulled hair away from scalp were in telogen phase and hair with white clubbed bulb [8].

The diagnosis of TE depended on history and physical examination and confirmed by a hair pull test.

\section{Statistical analysis}

Statistical Package for Social Science (SPSS) version 22 was used for data input and analysis. Data were statistically described in terms of mean, standard deviation (SD), frequencies (no. of cases), male-to-female ratio, and percentage $(\%)$.

\section{Results}

Thirty-nine patients were evaluated; their ages ranged from 22 to 67 years with a mean and SD of $41.3 \pm 11.6$ years with $36(92.3 \%)$ females and $3(7.69 \%)$ males.

All patients with a diagnosis of ATE were enrolled in this study and had a laboratory-confirmed diagnosis of prior SARS-CoV-2 infection; 15 (38.46\%) patients reported mild COVID symptoms, $24(61.53 \%)$ patients presented with moderate disease, and no patient required hospitalization. They all experienced excessive hair loss within 2-3 months after COVID-19 infection, which included hair coming out in large clumps.
All patients had the symptoms of SARS-CoV-2 infection, and they had received all or part of the National Guidance for Clinical Management and Treatment of COVID-19 for the treatment of mild and moderate COVID-19 infection [antiviral therapy (favipiravir tablet for mild disease, favipiravir tablet or lopinavir-ritonavir tablet for moderate infection), antibiotics (ceftriaxone injection, oral azithromycin, or oral levofloxacin), dexamethasone injection, anticoagulant (enoxaparin), supportive therapy (antipyretics, tonics such as, zinc, selenium, and vitamins $\mathrm{D}$ and $\mathrm{C}$ ), and oxygen $\left(\mathrm{O}_{2}\right)$ ].

On dermatologic examination, the pull tests were strongly positive ( $>10-50 \%$ with a mean of $35 \%$ of pulled hair away from scalp), and this indicated moderate to severe hair telogen shedding. Also moderate to severe reduced hair density was observed, and the pattern of hair loss showed that $43.58 \%$ were of the diffuse type (most common), $30.76 \%$ of bitemporal type, $12.82 \%$ occipital, $7.69 \%$ frontovertical, and $5.12 \%$ bitemporo-frontal. There were no alopecic patches or scaling, erythema, or other dermatological abnormalities (Figs. 1, 2, and 3).

\section{Discussion}

Acute telogen effluvium is a well-documented disease of females for the following reasons: (1) Females are more susceptible for stress commonly delivery, abortion, and others. (2) Females are more disturbed by hair shedding than males and are therefore more likely to seek medical attention. (3) Long hair is more easily noticed by the females during hair shedding while among males is rarely reported as there is short hair [4].

TE usually occurs 2 to 3 months following trigger events, including severe infective episodes [4]. In published

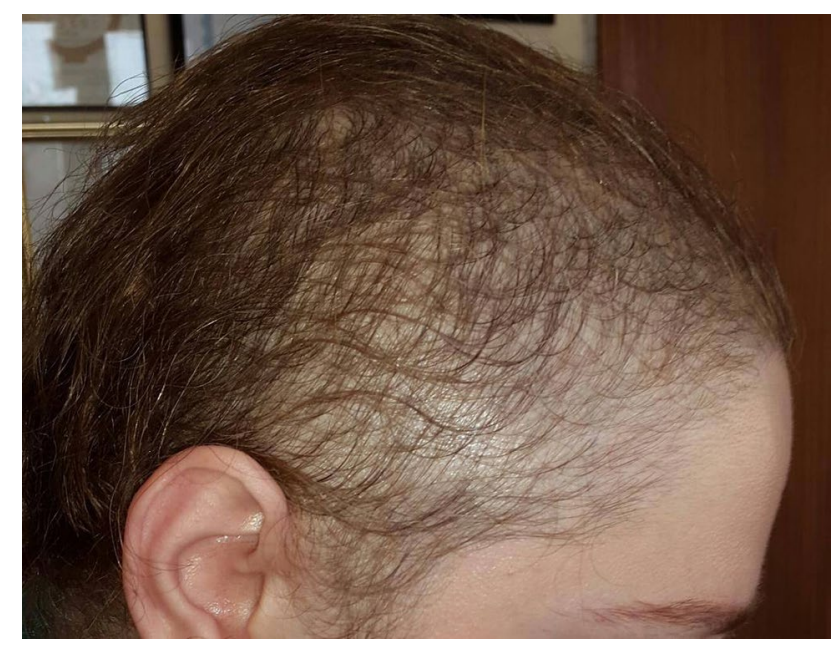

Fig. 1 Thirty-two-year-old female patient with severe acute telogen effluvium (diffuse) where the hair pull test is $>40 \%$ 


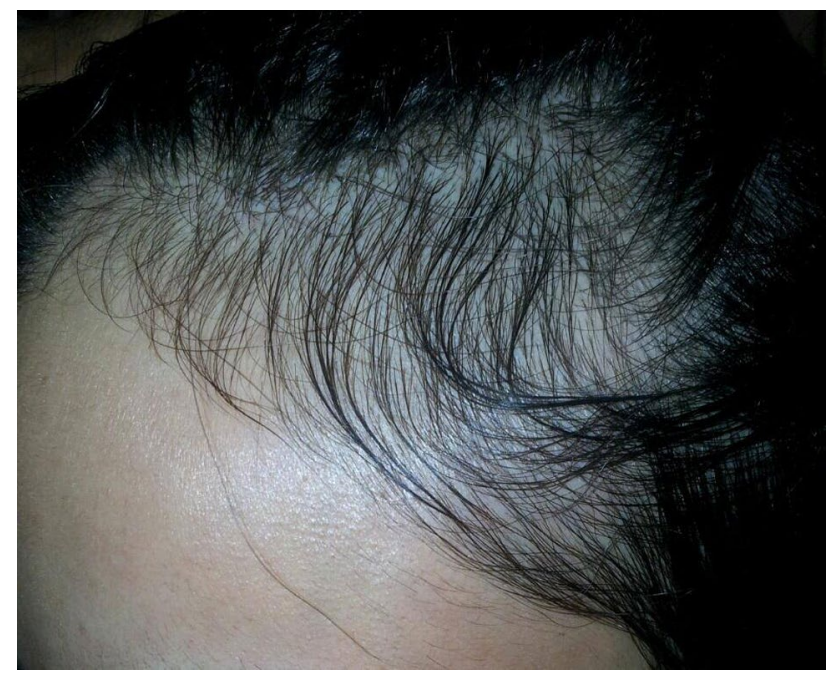

Fig. 2 Twenty-two-year-old female patient showing acute telogen effluvium (bitemporo-frontal) where hair pull test is around $20 \%$

literature, the association of ATE with dengue fever, influenza, human immunodeficiency virus infection, typhoid fever, scarlet fever, pneumonia, tuberculosis, pertussis, and malaria have already been recorded $[9,10]$.

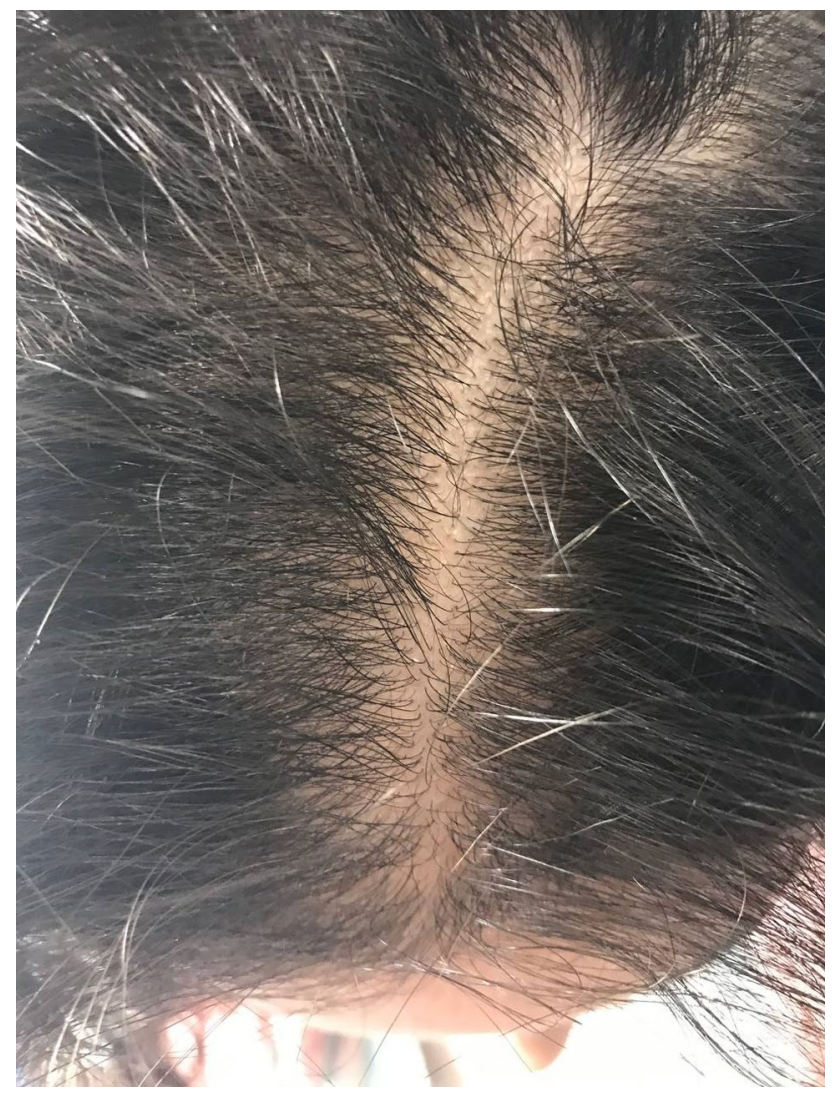

Fig. 3 Twenty-eight-year-old female with acute telogen effluvium (diffuse) and hair pull test around $25 \%$
In particular, patients with SARS-CoV-2 infection showed a consistent increase in proinflammatory cytokines (tumor necrosis factor $\alpha$, interleukin $1 \mathrm{~b}$, interleukin 6 , and types 1 and 2 interferon) [11] which can explain infectionrelated skin manifestations, such as livedoid vasculopathy, urticaria, COVID toes, and chicken pox-like rash [12]. Cytokine storm can initiate the development of TE by damaging the matrix cells [13], and usually, the high levels of interferons have already been confirmed to be associated with ATE [14].

Hoffmann et al. [15] demonstrated that SARS-CoV-2 utilized the transmembrane protease serine 2 (TMPRSS2) for $\mathrm{S}$ protein priming and the SARS-CoV receptor angiotensinconverting enzyme 2 (ACE2) for entrance. Therefore, any cell that carries the ACE2 receptor including the skin is a potential target for SARS-CoV-2. A recent study [16] has identified SARS-CoV-2 in the sweat duct and sweat glands of COVID-19 patients. To further elucidate the definite mechanism of TE following COVID-19 infection, additional studies of hair follicle tissue are required.

There are previous articles that recorded a relationship between COVID-19 and hair fall. In a large-scale study (538 cases) in Wuhan, China [17], investigating clinical sequelae of COVID-19, the prevalence of alopecia as a sequela was detected in $28.6 \%$ of patients. Moreno-Arrones et al. evaluated 191 patients with ATE that had prior SARS-CoV-2 infection, $78.5 \%$ of whom were females; $75 \%$ of the patients had received various therapies for COVID-19. They suggested that proinflammatory cytokines released during the infection condition may initiate TE [18].

To the best of knowledge, this is the first study in Iraq that highlights the relation between COVID-19 and ATE and investigated the etiopathogenesis of hair shedding during the pandemic of this virus infection.

In the current work, the patients have been treated with a multi-drug regime according to the National Guidance for Clinical Management and Treatment of COVID-19 for the treatment of mild and moderate COVID-19 infection. However, an implication of enoxaparin in the development of ATE cannot be ruled out. Watras et al. [19] shed light on the role of anticoagulants, including enoxaparin [20] in TE. They described that TE started 3 weeks after drug administration while in the present study the hair shedding began 2-3 months after the COVID-19 infection. The median dose used in the study (100 IU/kg twice a day) was higher than that in our cases (about $75 \mathrm{IU} / \mathrm{kg}$ once a day as a prophylactic and $75 \mathrm{IU} /$ $\mathrm{kg}$ twice a day as a therapeutic); thus, it seems less reasonable that enoxaparin is the cause of ATE rather than the COVID19 infection. Other drugs, antivirals, ceftriaxone, antipyretics, dexamethasone, and tonics which are used for the treatment of our patients, were excluded as a cause of ATE, as these drugs are not mentioned in the literature as a cause of ATE. On contrary, tonics especially zinc may enhance hair regrowth [21]. 
Increased psychosocial tension may have an effect on the course of many skin conditions, leading to a real exacerbation of the disease $[22,23]$. This is true particularly for TE, a disease mostly induced by stressful conditions $[24,25]$. The relationship between a stressor and any later change in the hair growth cycle has resulted in the nomination of a brain-hair follicle axis. In particular, the release of specific neurotransmitters, neuropeptides, and hormones along this axis may promote remarkable changes in the hair growth cycle by stimulating the shifting of anagen hair into the telogen phase.

TE has become a standard sequela, which seriously affects the psychosocial condition of patients who recovered from COVID-19. Also, the COVID-19 epidemic has an impression on social lifetime of people, and some subjects are more susceptible to depression and anxiety, from which TE may occur [17].

\section{Conclusion}

ATE is a non-scaring diffuse hair loss, usually occurs 3 months after the event that causes hair loss, and lasts up to 6 months. Recently, the percentage of ATE among other forms of hair loss is increased in comparison with previous years; this could be attributed to the pandemic of COVID19 during this period. The exact mechanisms by which this virus induces hair loss are not well known, but the most acceptable one is the release of cytokine storm during the infection with this virus, and this process can initiate TE development by damaging hair matrix cells. Also, the psychosocial condition of patients who recovered from COVID19 was seriously affected. The COVID-19 epidemic has an impression on social lifetime of people, and some subjects are more susceptible to depression and anxiety, from which TE may occur. Drugs that have been received by our patients during treatment of COVID-19 were excluded as a cause of ATE. Finally, further researches are encouraged to reach the precise etiopathogenesis of the condition.

Data availability Any further data and material can be provided through contacting the corresponding author.

\section{Declarations}

Ethics approval The ethics committee simply required the written statement of consent by the patient.

Consent to participate There is informed consent of participation by the patient.

Consent for publication There is informed consent of publication by the patient.
Competing interests The authors declare no competing interests.

\section{References}

1. Hui DS, Azhar EI, Madani TA et al (2020) The continuing 2019nCoV epidemic threat of novel coronaviruses to global healththe latest 2019 novel coronavirus outbreak in Wuhan. China Int J Infect Dis 91:264-266. https://doi.org/10.1016/2Fj.ijid.2020.01. 009 (PMID: 31953166)

2. Jewell NP, Lewnard JA, Jewell BL (2020) Caution warranted: using the Institute for health metrics and evaluation model for predicting the course of the COVID-19 pandemic. Ann Intern Med 173:226-227. https://doi.org/10.7326/m20-1565 (PMID: 32289150)

3. Galván Casas C, Català A, Carretero Hernández G et al (2020) Classification of the cutaneous manifestations of COVID-19: a rapid prospective nationwide consensus study in Spain with 375 cases. Br J Dermatol 183(1):71-77. https://doi.org/10.1111/bjd.19163

4. Malkud S (2015) Telogen effluvium: a review. J Clin Diagn Res 9(9):WE01- WE03. https://doi.org/10.7860/2FJCDR/2F2015/ 2F15219.6492 PMID: 26500992

5. Torres F, Tosti A (2015) Female pattern alopecia and telogen effluvium: figuring out diffuse alopecia. Semin Cutan Med Surg 34(2):67-71. https://doi.org/10.12788/j.sder.2015.0142 PMID: 26176282

6. Stenn KS, Paus R (2001) Controls of hair follicle cycling. Physiol Rev (1);81:449-494. https://doi.org/10.1152/physrev.2001.81.1. 449 PMID: 11152763

7. Amor KT, Rashid RM, Mirmirani P (2010) Does D matter? The role of vitamin D in hair disorders and hair follicle cycling. Dermatol Online J 16(2):3 (PMID: 20178699)

8. Dhurat R, Saraogi P (2009) Hair evaluation methods: merits and demerits. Int J Trichology 1:108-19. https://doi.org/10.4103/ 2F0974-7753.58553 PMID: 20927232

9. Chu CB, Yang CC (2017) Dengue-associated telogen effluvium: a report of 14 patients. Dermatol Sin 35(3):124-126. https://doi. org/10.1016/J.DSI.2017.03.005

10. Bernstein GM, Crollick JS, Hassett JM Jr (1988) Postfebrile telogen effluvium in critically ill patients. Crit Care Med 16:98-99. https://doi.org/10.1097/00003246-198801000-00020 (PMID: 3338284)

11. Ye Q, Wang B, Mao J (2020) The pathogenesis and treatment of the cytokine storm in COVID-19. J Infection 80(6):607-613. https://doi.org/10.1016/j.jinf.2020.03.037 (PMID: 32283152)

12. Diotallevi F, Campanati A, Bianchelli T et al (2020) Skin involvement in SARS-CoV-2 infection: case series. J Med Virol 92:23322334. https://doi.org/10.1002/jmv.26012 (PMID: 32410241)

13. Headington JT (1993) Telogen effluvium. New concepts and review Arch Dermatol 129(3):356-363. https://doi.org/10.1001/ archderm.129.3.356 (PMID: 8447677)

14. Olsen EA, Rosen ST, Vollmer RT et al (1989) Interferon alfa-2a in the treatment of cutaneous T cell lymphoma. J Am Acad Dermatol 20(3):395-407. https://doi.org/10.1016/s0190-9622(89)70049-9 (PMID: 2783939)

15. Hoffmann M, Kleine-Weber H, Schroeder S et al (2020) SARSCoV-2 cell entry depends on ACE2 and TMPRSS2 and is blocked by a clinically proven protease inhibitor. Cell 181(2):271-280. https://doi.org/10.1016/j.cell.2020.02.052 (PMID: 32142651)

16. Liu J, Li Y, Liu L et al (2020) Infection of human sweat glands by SARS-CoV-2. Cell Discov 6(1):84. https://doi.org/10.1038/2Fs41421020-00229-y (PMID: 33298845)

17. Xiong Q, Xu M, Li J et al (2021) Clinical sequelae of COVID-19 survivors in Wuhan, China: a single-centre longitudinal study. 
Clin Microbiol Infect 27(1):89-95. https://doi.org/10.1016/j.cmi. 2020.09.023 (PMID: 32979574)

18. Moreno-Arrones OM, Lobato-Berezo A, Gomez-Zubiaur A et al (2021) SARS-CoV-2-induced telogen effluvium: a multicentric study. J Eur Acad Dermatol Venereol 35(3):e181-e183. https:// doi.org/10.1111/jdv.17045 (PMID: 33220124)

19. Watras MM, Patel JP, Arya R (2016) Traditional anticoagulants and hair loss: a role for direct oral anticoagulants? A review of the literature. Drugs Real World Outcomes 3(1):1-6. https://doi. org/10.1007/s40801-015-0056-z (PMID: 27747798)

20. Wang YY, Po HL (2006) Enoxaparin-induced alopecia in patients with cerebral venous thrombosis. J Clin Pharm Thera 31(5):513517. https://doi.org/10.1111/j.1365-2710.2006.00769.x (PMID: 16958830)

21. Goskowicz M, Eichenfield LF (1993) Cutaneous findings of nutritional deficiencies in children. Curr Opin Pediatr 5(4):441-445. https://doi.org/10.1097/00008480-199308000-00012
22. Garcovich S, Bersani FS, Chiricozzi A, De Simone C (2020) Mass quarantine measures in the time of COVID-19 pandemic: psycho-social implications for chronic skin conditions and a call for qualitative studies. J Eur Acad Dermatol Venereol 34:293-294. https://doi.org/10.1111/jdv.16535 (PMID: 32330329)

23. Jafferany M, Franca K (2016) Psychodermatology: basics concepts. Acta Derm Venereol 96(217):35-37. https://doi.org/10. 2340/00015555-2378 (PMID: 27282585)

24. Rebora A (2019) Telogen effluvium: a comprehensive review. Clin Cosmet Investig Dermatol 12:583-590. https://doi.org/10.2147/ ccid.s200471 (PMID: 31686886)

25. Alexopoulos A, Chrousos GP (2016) Stress-related skin disorders. Rev Endocr Metab Disord 17(3):295-304. https://doi.org/10.1007/ s11154-016-9367-y (PMID: 27368716)

Publisher's Note Springer Nature remains neutral with regard to jurisdictional claims in published maps and institutional affiliations. 